\title{
Phytochemicals in leaves of Cotoneaster mongolica, their antioxidative, and acetylcholinesterase inhibitory activity
}

\author{
Odontuya Gendaram
}

\author{
Institute of Chemistry and Chemical Technology, Mongolian Academy of Sciences, \\ 4th Building of MAS, Ulaanbaatar, 13330, Mongolia
}

*Corresponding author: odontuyag@mas.ac.mn; ORCID ID:0000-0002-4924-0932

Received: 26 April 2019; revised: 23 October; accepted: 9 November 2019

\begin{abstract}
The phytochemicals in the leaves of Cotoneaster mongolica Pojark, as well as their antioxidant and acetylcholinesterase (AChE) inhibitory activity, were studied. The methanol extract of the leaves showed acetylcholinesterase inhibitory activity $\left(\mathrm{IC}_{50}, 32.61 \pm 0.51 \mathrm{\mu g} / \mathrm{mL}\right)$. The $n$-butanol fraction of this extract exhibited DPPH radical scavenging $\left(\mathrm{IC}_{50}, 55.70 \pm 0.15\right.$ $\mu \mathrm{g} / \mathrm{mL})$ and AChE inhibitory activity $\left(\mathrm{IC}_{50}, 72.50 \pm 0.60 \mu \mathrm{g} / \mathrm{mL}\right)$. From the $n$-butanol fraction quercetin (1), hyperoside (2), kaempferol-5-O- $\beta$-D-glucopyranoside (3), sissotrin (4), ursolic acid (5), corosolic acid (6), euscaphic acid (7), prunasin (8), $(2 R)$-mandeloyl- $\beta$ - $D$-glucopyranose (9), (Z)-3-hexenyl-O- $\alpha$ - $L$-rhamnopyranosyl-( $1 \rightarrow 6)-\beta$ - $D$-glucopyranoside (10), benzyl$O-\alpha$-L-rhamnopyranosyl-(1 $\rightarrow 6)-\beta-D$-glucopyranoside (11) and arbutin (12) have been isolated and identified. Hyperoside, one of the major constituents among the isolated compounds, was active in both tested assays. Flavonol derivatives could provide the activity of this plant species.
\end{abstract}

Keywords: Cotoneaster mongolica, prunasin, hyperoside, DPPH scavenging, AChE inhibition

\section{INTRODUCTION}

In the Mongolian flora, the genus Cotoneaster (Rosaceae) contains 4 represented species: C.mongolica. Pojark., C.megalocarpa M.Pop., C.melanocarpa Lodd. and C.uniflora Bge. [1-3]. Fruits, shoots, twigs and leaves of Cotoneaster species as crude drugs are mainly used in the form of infusion, extract, tincture, tea and juice in traditional Mongolian medicine for the cure of intestinal inflammatory diseases, diarrhea, stomach indigestion, bowel disorders and abdominal cavity ascites, as well as rheumatoid arthritis. Fruits of C.mongolica, (rarely C.melanocarpa) under a Tibetan name "dat-rig" is the major component of the complex formulation "dat-rig 9", which supports digestion and "dat-rig 7", effective for the treatment of diarrhea [2, 3]. Moreover, Cotoneaster species occurring in Russia, Iran, Uzbekistan, Turkey and Caucasia are used in traditional medicine, especially for the treatment of neurasthenia, nervous prostration, nasal hemorrhage, excessive menstruation, neonatal jaundice and cough [4-6]. Besides medicinal utilization, some shrubs of the Cotoneaster genus are used as ornamental plants, for which some species were cultivated as a small bonsai with flowers and fruits $[7,8]$. C.mongolica is a sub-indigenous deciduous shrub. Isoquercetin, quercitrin, rutin and isoorientin, quercetinglycosides, were identified in the leaf samples of C.mongolica Pojark with HPLC method [9]. However, no data were found on the biological activity of this plant species.In this study, phytochemicals in the leaves of C.mongolica, their antioxidant and acetylcholinesterase inhibitory activity were investigated.

\section{EXPERIMENTAL}

General experimental procedures: Thin layer chromatography (TLC) was performed on pre-coated silica gel $60 \mathrm{~F}_{254}$ plate (Merck, Darmstadt, Germany) and the spots were detected under UV radiation $(365 \mathrm{~nm})$ by spraying with $1 \%$ methanolic diphenylboric acid- $\beta$ ethylamino ester (NP) and $5 \%$ ethanolic polyethylene glycol (PEG); under visible light by spraying and heating at $100-105{ }^{\circ} \mathrm{C}$ with $5 \%$ sulfuric acid; $1 \%$ vanillin and $5 \%$ sulfuric acid. Silica gel 60 (40-60 $\mu \mathrm{m}$, Merck, Darmstadt, Germany) Sephadex LH-20 (25-100 mm, Pharmacia, Uppsala, Sweden), MCI gel-CHP-20P (75$150 \mu \mathrm{m}$, Mitsubishi Chemical Corporation, Japan) and 
Sepra $^{\text {TM }}$ C18-E $(50 \mu \mathrm{m}, 65 \AA)$ were used for column chromatography (CC). NMR spectra were recorded on Bruker AM-300 Spectrometer in $\mathrm{MeOH}-d_{4}{ }^{1} \mathrm{H}$ (300 $\mathrm{MHz}$ ) and ${ }^{13} \mathrm{C}(75 \mathrm{MHz})$. UV spectroscopic analysis was carried on a spectrophotometer UV-160 (Shimadzu, Japan). Mass spectra were carried out at $70 \mathrm{eV}$. All reagents and solvents used were of analytical grade.

Plant materials: Leaves and fruits of Cotoneaster mongolica Pojark were collected from shrubs grown alongside the dry, rocky creek, in the vicinity (Khailaast) of Ulaanbaatar, Mongolia ( $47^{\circ} 57^{\prime} \mathrm{N}, 106^{\prime} 53^{\prime} \mathrm{E}$ ), in September 2005. Prof. Sanchir Ch., in Institute of Botany, Mongolian Academy of Sciences, authenticated the plant specimen. The voucher specimen $(\mathrm{Cm}$ 050911) was deposited in the Herbarium of the Natural Product Chemistry Laboratory of ICCT, MAS.

Extraction and fractionation: The air-dried and powdered leaves of C.mongolica $(400 \mathrm{~g})$ were macerated with pure $\mathrm{MeOH}(3 \times 1200 \mathrm{~mL}$, each $24 \mathrm{~h})$ and $70 \% \mathrm{MeOH}$ twice $(2 \times 500 \mathrm{~mL}$, each $24 \mathrm{~h})$ at room temperature. The total extract was concentrated to dryness under reduced pressure. The concentrated solid $(119 \mathrm{~g})$ was reconstituted with $120 \mathrm{~mL}$ of dist. water, then partitioned successively with chloroform $(800 \mathrm{~mL})$, and $n$-butanol $\left(800 \mathrm{~mL}\right.$ ) to yield $42.3 \mathrm{~g} \mathrm{CHCl}_{3}$ and $32 \mathrm{~g} \mathrm{n}$-BuOH fractions (fr), respectively. The aqueous soluble residue (Wat. res, $40 \mathrm{~g}$ ), after fractionation, was kept for its free radical scavenging activity tests.

The air-dried and powdered fruits of C.mongolica $(115 \mathrm{~g})$ were macerated by $\mathrm{MeOH}(3 \times 300 \mathrm{~mL}$, each $24 \mathrm{~h})$ at room temperature. Each time the $\mathrm{MeOH}$ extract was concentrated to dryness in vacuo and combined to yield $17 \mathrm{~g}$ of thick extract.

The quality of phytoconstituents of all extracts and fractions were analyzed by TLC method with $\mathrm{CHCl}_{3}: \mathrm{MeOH}-9: 1$ and $\mathrm{CHCl}_{3}: \mathrm{MeOH}: \mathrm{H}_{2} \mathrm{O}-7: 3: 0.4$ solvent systems by spraying with NP/PEG for flavonoids and phenolics, $5 \%$ sulfuric acid and $1 \%$ vanillin / $5 \%$ sulfuric acid for terpenoids.

Separation and isolation: The $n-\mathrm{BuOH}$ fr. $(32 \mathrm{~g})$ was separated and divided into IX subfractions over silica gel 60 column $(5 \times 100 \mathrm{~cm})$, eluted gradiently with $\mathrm{CHCl}_{3}: \mathrm{MeOH}-99: 1,98: 2,95: 5,90: 10$ and $85: 15$. Subfractions I $(110 \mathrm{mg}), \mathrm{II}(115 \mathrm{mg})$ and $\mathrm{V}(1.17 \mathrm{~g})$ were subjected to sephadex $\mathrm{LH} 20 \mathrm{CC}$ eluted with $\mathrm{CH}_{2} \mathrm{Cl}_{2}$ : $\mathrm{MeOH}-1$ : 1. Subfractions II (313.2 mg), VI $(2.19 \mathrm{~g})$, VII $(1.15 \mathrm{~g})$, VIII (1.19 g) and IX (3.88 g) were subjected to $\mathrm{MCl}$ gel CHP 20P CC eluted with $10 \%, 20 \%, 40 \%$, $60 \%, 70 \%$, and $80 \% \mathrm{MeOH}$ in water, respectively. Subfraction III (74.2 mg) was separated over silica gel 60 column with the solvent $\mathrm{CH}_{2} \mathrm{Cl}_{2}: \mathrm{MeOH}-98: 2$. The final purification and isolation of all 1-12 compounds were carried out by CC using sephadex LH 20 or C 18 -E eluting with $10 \%, 20 \%, 30 \%, 40 \%, 50 \% \mathrm{MeOH}$ in water.

Compound $\mathbf{1}(10 \mathrm{mg})$ was isolated from the subfractions VII and VIII, 2 (559.7 mg), 3 (9.0 mg), 11 (185.7 mg) and $12(36.1 \mathrm{mg})$ from the IX, $4(17.1 \mathrm{mg})$ from the $V$ and VI, 5 (59.4 $\mathrm{mg})$ from the I and II, $6(11.7 \mathrm{mg})$ from the II and IV, $7(37.4 \mathrm{mg})$ from the II, $8(2.38 \mathrm{~g})$ from the II - VIII, $9(131.4 \mathrm{mg})$ and $\mathbf{1 0}(43 \mathrm{mg})$ from the VII and IX.

Acid hydrolysis: Each compound (2, 3 or $\mathbf{8}, 2-5 \mathrm{mg})$ in vials was added $2 \mathrm{~mL} 2 \mathrm{~N} \mathrm{HCl}$ in $\mathrm{MeOH}$ and the vial was capped tightly. The vial was heated for 3 hours at $100^{\circ} \mathrm{C}$. After being allowed to cool, the solution was diluted with dist. water $(5 \mathrm{~mL}) .10 \mathrm{~mL}$ of ethylacetate (EA) was added, and the solution was shaken vigorously for 2 minutes. The two phases were allowed to separate, then the organic (top) layer was pipetted off and collected in another vial. This procedure was repeated 2 more times with EA, collecting a total of EA extract into the vial and reducing the volume of the extract. Aglycones were identified by comparing them with corresponding authentic quercetin and kaempferol in TLC developed with $\mathrm{CHCl}_{3}: \mathrm{MeOH}-9: 1$, and TLC was sprayed with NP / PEG and visualized under UV $365 \mathrm{~nm}$. The water residue after hydrolysis was evaporated and dissolved in a small amount of $\mathrm{MeOH}$ followed by the identification of sugars by TLC in comparison to standard ones. The TLC was developed with EA : $\mathrm{H}_{2} \mathrm{O}: \mathrm{MeOH}: \mathrm{CH}_{3} \mathrm{COOH}$ $-13: 3: 3: 4$ and sprayed with $5 \%$ sulfuric acid followed by heating at $100{ }^{\circ} \mathrm{C}$ for $10 \mathrm{~min}$. [10].

DPPH scavenging activity: DPPH radical (2,2-diphenyl-2-picrylhydrazyl hydrate, TCl, Co., Ltd) scavenging activity of the crude extracts, fractions and pure compounds was determined according to the known spectrophotometric assay [11]. The absorbance was measured at $517 \mathrm{~nm}$ and the anti-oxidative activity (AA) was expressed in percentage:

$$
A A \%=100-\left\{\left[\left(\mathrm{Abs}_{\text {sample }}-\mathrm{Abs}_{\text {blank }}\right) \times 100\right] / \mathrm{Abs}_{\text {control }}\right\} ;
$$

Methanol $(1.5 \mathrm{~mL})$ added to the plant extract solution $(1.5 \mathrm{~mL})$ was used as a blank. DPPH solution $(1.5 \mathrm{~mL}$, $\left.6 \times 10^{-5} \mathrm{M}\right)$ plus methanol $(1.5 \mathrm{~mL})$ was used as a control and rutin was used as a positive control.

Acetylcholinesterase inhibiting activity: The acetylcholinesterase inhibiting activity of crude extracts, fractions and isolated pure substances was determined using a previously reported Ellman spectrophotometric method with DTNB (5,5'-dithiobis(2-nitrobenzoisc acid), $\mathrm{TCl}, \mathrm{Co} ., \mathrm{Ltd})$ color reagent [12]. The absorbance was measured at $412 \mathrm{~nm}$ and the AChE inhibiting activity (I) was expressed in percentage:

$$
\mathrm{I}(\%)=100 \times\left(\text { Abs } 10_{\text {control }}-\Delta \mathrm{Abs}_{\text {sample }}\right) / \text { Abs } 10_{\text {control }}
$$

Where; $\Delta \mathrm{A}_{\text {sample }}=$ Abs $10 \mathrm{~min}_{\text {sample }}-$ Abs $00 \mathrm{~min}_{\text {sample }}$

Blank solution was prepared from $0.1 \mathrm{~mL}$ sample $(1 \mathrm{mg} /$ $\mathrm{mL}$ ) with DTNB prepared in Tris- $\mathrm{HCl}$, while the positive control was prepared from DMSO (dimethylsulfoxide) with the same amount of the sample. Eserin (physostigmine, $\mathrm{TCl}, \mathrm{Co}$., Ltd) was used as a positive control. 
Statistical analysis: The results were expressed as mean values and standard deviation (mean $\pm S D$ ). Student's $t$-test at a level of $p<0.05$ was considered as statistically significant. The $I C_{50}$ value, defined as the amount of the sample that could reduce the initial concentration of DPPH and AChE by $50 \%$, was calculated from the linear regression plots of test samples concentration against the mean inhibition in percentage. $I_{50}$ values were calculated using concentration of tested plant extracts, fractions and isolated substances and average percent of the antioxidant activity from three separate tests, and AChE inhibiting activities 6-8 separate tests.

\section{RESULTS AND DISCUSSION}

The methanol extract of leaves of C.mongolica and its derived chloroform and $n$-butanol fractions, including water residue, as well as the methanol extract of fruits were evaluated for their anti-oxidative and AChE inhibitory activities (Table 1 and 2).

Table 1. Results of the DPPH radical scavenging activity, $\mathrm{IC}_{50} \pm \mathrm{SD}(\mu \mathrm{g} / \mathrm{mL})$

\begin{tabular}{lll}
\hline Extracts and fractions & Leaves & Fruits \\
\hline Methanol extract & $>200$ & $108.50 \pm 0.71$ \\
Chloroform fraction & $>200$ & - \\
n-Butanol fraction & $55.70 \pm 0.15$ & $>200$ \\
Water residue & $>200$ & - \\
Standard - Rutin & & $22.66 \pm 0.15$ \\
\hline
\end{tabular}

Notice: - - not screened;

Table 2. Results of the AChE inhibition activity, $\mathrm{IC}_{50} \pm \mathrm{SD}(\mu \mathrm{g})$

\begin{tabular}{lll}
\hline Extracts and fractions & Leaves & Fruits \\
\hline Methanol extract & $32.60 \pm 0.51$ & $45.0 \pm 0.50$ \\
Chloroform fraction & $405.60 \pm 0.92$ & - \\
$n$-Butanol fraction & $72.50 \pm 0.60$ & - \\
Water residue & $442.35 \pm 0.64-$ \\
Standard - Physostigmine & \multicolumn{2}{c}{0.228} \\
\hline
\end{tabular}

Notice: - - not screened;

Among all the DPPH assayed crude extracts and fractions, only $n$-butanol fraction of leaves exhibited higher activity $\left(\mathrm{IC}_{50}, 55.70 \pm 0.15 \mu \mathrm{g} / \mathrm{mL}\right)$; however, the activity was half that of standard rutin. The methanol extracts of both leaves and fruits and the $n$-butanol fraction of leaves showed AChE inhibitory activity $\left(\mathrm{IC}_{50}\right.$, $32.61 \pm 0.51 \mu \mathrm{g}, 44.97 \pm 0.50 \mu \mathrm{g}$, and $72.50 \pm 0.60 \mu \mathrm{g}$ ). Over the past years, the anti-oxidative activity of several species of Cotoneaster has been assayed by the hydrogen donating DPPH radical scavenging method. The anti-oxidative activity of $70 \%$ methanol extracts of leaves from 12 species of Cotoneaster Medik. varied between $\mathrm{EC}_{50}, 18.5-34.5 \mu \mathrm{g} / \mathrm{mL}$ [13]. The leaf methanol extract of C.melanocarpus showed activity with $\mathrm{IC}_{50}, 106.41 \mu \mathrm{g} / \mathrm{mL}$ [4]. The twig ethanol extract of C.horizontalis possessed high scavenging activity of $I_{50}, 19.3 \mu \mathrm{g} / \mathrm{mL}$ [14], compared to the same crude drug methanol extracts of C.nummularia $\left(\mathrm{IC}_{50}, 104.0 \mathrm{mg} / \mathrm{mL}\right)$ [15] and C.integerrimus $\left(\mathrm{IC}_{50}, 1.06 \mathrm{mg} / \mathrm{mL}\right)$ [16]. The variability in results of different species of Cotoneaster depends on many reasons, in particular on various natures of phytochemicals and their contents.

Previously, the AChE inhibitory activity of the twig and fruit methanol extracts of C.integerrimus was determined with results $\mathrm{IC}_{50}, 1.07 \mathrm{mg} / \mathrm{mL}$ and $1.72 \mathrm{mg} / \mathrm{mL}$, while the twig methanol extract of C.nummularia gave 4.77 mg GALAEs/g (galanthamine equivalent) extract, respectively $[15,16]$. In our experiments, methanol extracts of C.mongolica leaves and fruits at $1 \mathrm{mg} / \mathrm{mL}$ concentration exhibited comparable activities against AChE enzyme with over $60 \%$ inhibition, which is the same level as ethanol extract, ethylacetate and $n$-butanol fractions of Dasiphora fruticosa leaves, as well as the ethylacetate fraction of Myricaria alopecuroides branches [17]. The experiments were carried out in the same conditions. In contrast to methanol extract, it was observed that the $n$-butanol fraction showed lower AChE inhibitory activity. This phenomen could be explained by the presence of both various classes of nonpolar and polar compounds with greater enzyme inhibitory activity in the methanol extract than the polar compounds, which are predominantly extracted in the $n$-butanol fraction. In particular, it is likely that the nonpolar aglycones extracted in the methanol fraction are responsible for much of enzyme inhibitory activity present in the leaves. Thus, the biological activity of extracts and fractions depends on the complex nature of phytochemicals and their synergistic and antagonistic effects [15].

In this study, 12 compounds have been isolated from the $n$-butanol fraction, including quercetin (1) $[18,19]$, hyperoside (2) [20], kaempferol-5-O- $\beta-D-$ glucopyranoside (3) [21], sissotrin (4) [22], ursolic acid (5) [23, 24], corosolic acid (6) [24], euscaphic acid (7) [24], prunasin (8) [25], (2R)-mandeloyl- $\beta$ $D$-gluco pyranose (9) [26], (Z)-3-hexenyl-O- $\alpha$ - Lrhamnopyranosyl-(1 $\rightarrow 6)-\beta$ - $D$-glucopyranoside $\quad(10)$ [27], benzyl-O- $\alpha$ - $L$-rhamnopyranosyl-( $1 \rightarrow 6)-\beta$ - $D$-gluco pyranoside (11) [28] and arbutin (12) [29], respectively (Figure 1). They were identified on the basis of their physicochemical properties and spectral data. The sugars in the glycosides $(2,3$ and $\mathbf{8})$ were characterized by acidic hydrolysis.

The phytochemical investigation of leaf, twig and fruit samples of other Cotoneaster species indicated that flavonoids, cyanogenic glycosides and triterpenoids are the main secondary metabolites in these plants. In this study, $2.38 \mathrm{~g}$ prunasin (8), a cyanogenic glycoside, was isolated. The presence of prunasin and amygdalin in the leaves and fruits of Cotoneaster-Arten was confirmed by gas-liquid chromatography [30]. 


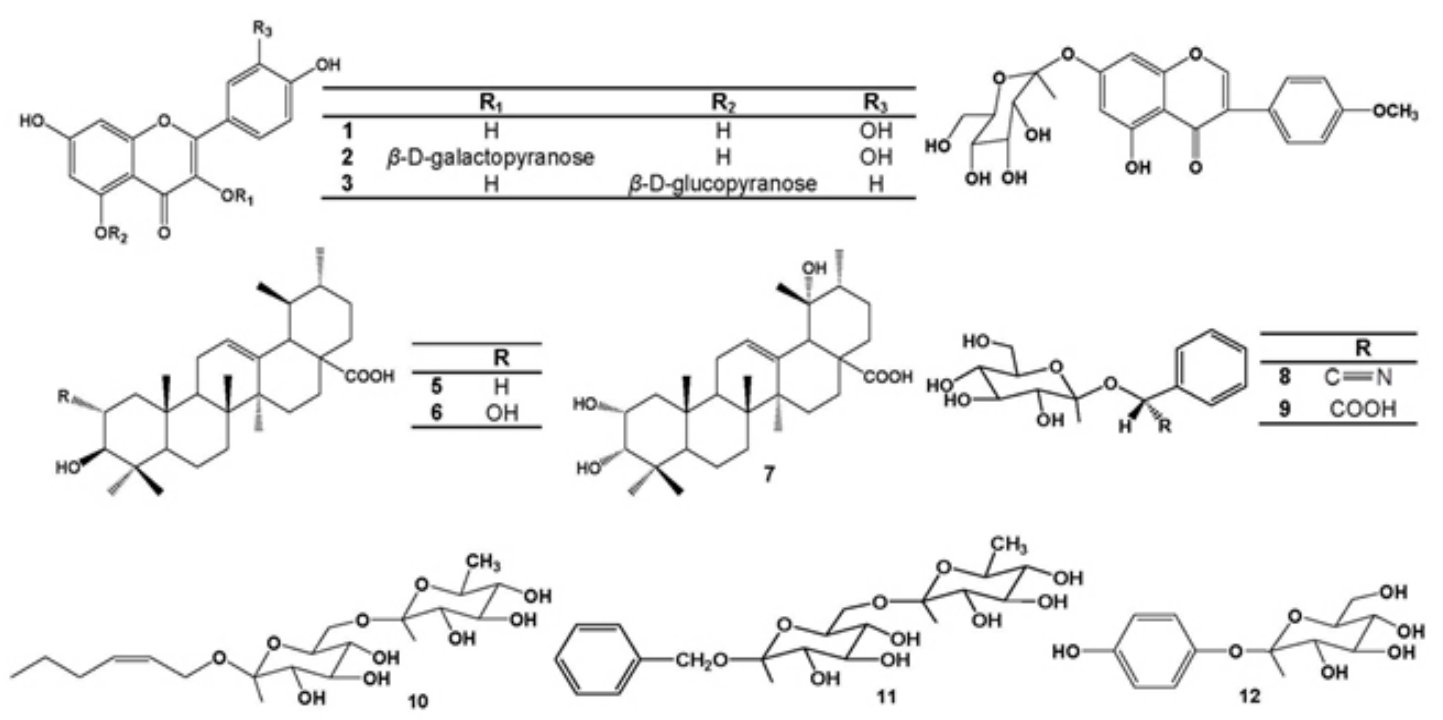

Fig. 1. Compounds 1 - 12 isolated from leaves of C.mongolica Pojark.

Hyperoside (2), a second rich flavonol glycoside, identified in leaf samples of 12 Cotoneaster Medik. species and C.melanocarpus by HPLC analysis, was isolated [13, 4]. In addition, quercetin (1) was identified in the twig of C.integerrimus [16], and ursolic acid (5), corosolic acid (6), euscaphic acid (7) and arbutin (12), respectively were identified in the leaves of $C$.simonsii by HPLC analysis [31]. Compounds 3, 4, 9, 10, 11 were isolated, and identified for the first time from C.mongolica.

All isolated compounds were tested for their antioxidant effect and AChE inhibitory activity by the previously described methods. Results are given in Table 3.

Table 3. Anti-oxidative and AChE inhibitory activities of isolated compounds

\begin{tabular}{lll}
\hline Compounds & $\begin{array}{l}\text { DPPH scavenging } \\
\text { activity, } \mathrm{IC}_{\mathbf{5 0}}, \boldsymbol{\mu M}\end{array}$ & $\begin{array}{l}\text { AChE inhibiting } \\
\text { activity, } \mathbf{I C}_{50}, \mathbf{m M}\end{array}$ \\
\hline 1 & $41.36 \pm 0.89$ & $\mathbf{0 . 1 1 0} \pm 0.001$ \\
2 & $\mathbf{1 8 . 9 3} \pm \mathbf{0 . 7 2}$ & $\mathbf{0 . 0 2 1} \pm \mathbf{0 . 0 0 2}$ \\
3 & $156.72 \pm 1.10$ & $\mathbf{0 . 0 5 3} \pm \mathbf{0 . 2 3}$ \\
4 & na & $1.530 \pm 0.11$ \\
5 & na & $0.306 \pm 0.003$ \\
6 & na & ns \\
\hline 7 & na & $1.567 \pm 0.09$ \\
8 & na & $2.072 \pm 0.23$ \\
9 & na & $2.519 \pm 0.09$ \\
\hline 10 & na & $2.340 \pm 0.10$ \\
11 & na & $1.960 \pm 0.06$ \\
\hline 12 & ns & ns \\
\hline Rutin & $\mathbf{3 8 . 7}$ & \\
\hline Physostigmine & & $\mathbf{0 . 0 0 0 0 8 3}$ \\
\hline
\end{tabular}

Notice: na - not active; - - not screened;
Biological activity analysis indicated that flavonoid derivatives were distinguished by high activities in both examined assays over other classes of isolated compounds. In particular, compound 2 was most active as an antioxidant and as an AChE enzyme inhibitor. Quercetin (1) was the second most active compound, which exhibits excellent DPPH scavenging activity with a wide range of values $\mathrm{IC}_{50}, 95 \mathrm{nM}-226 \mu \mathrm{M}$ [32]. Quercetin was also well studied for its AChE inhibitory activity. Researchers of different groups suggested that quercetin exhibited remarkable inhibitory activity with the $\mathrm{IC}_{50}, 19.8 \mu \mathrm{M}$ [33], the inhibitory activity $76.2 \%$ [34] and the inhibition zone $0.6 \mathrm{~cm}$ [35], respectively. Compound 3 demonstrated a low activity for both DPPH scavenging and AChE enzyme inhibition. All other tested components showed no activities. Consequently, it has been shown that the presence of hyperoside in considerable quantity causes anti-oxidative and AChE inhibitory activities in the leaf sample of C.mongolica. Hyperoside widely occurs in the plant kingdom and it demonstrates definite free radical scavenging and oxidative stress protective activity, as well as antiinflammatory, anti-thrombotic, anti-diabetic, anti-viral, anti-fungal and hepatoprotective effects [36-38]. In a study by Zhao Y. et al., hyperoside exhibited DPPH scavenging and AChE inhibition activities by the $\mathrm{IC}_{50}$, $11.19 \mu \mathrm{M}$ and $94.61 \mu \mathrm{M}$ (or $0.0946 \mathrm{mM}$ ), respectively, which to a certain degree is comparable to our results. Flavonoids are well-known antioxidants. According to the literature survey, both anti-oxidative and AChE inhibitory activities of various flavonoid aglycones and glycosides are related to their structural features. The presence of multiple $\mathrm{OH}$ groups in $\mathrm{A}$ and $\mathrm{B}$ rings, and unsaturation of the $\mathrm{C}$ ring produces a positive effect on the biological activity [32, 39]. In this study, anti-oxidative and AChE inhibitory activities of the main compound prunasin were assayed for the first time. However, it did not exhibit any AChE inhibition or anti-oxidative activity. 


\section{CONCLUSIONS}

The study of Cotoneaster mongolica leaves indicated that the methanol extract exhibited the highest acetylcholinesterase inhibitory, while the $n$-butanol fraction exhibited the highest DPPH radical scavenging activities. The latter fraction also showed activity against acetylcholinesterase enzyme. Flavonol derivatives, isoflavoneglycoside, phenol derivatives, triterpenoid acids, cyanogenic glycoside and olefinylglycoside were isolated from the $n$-butanol fraction. Hyperoside and its aglycone quercetin reflected the antioxidative and AChE inhibitory activities of the leaf sample. These results may provide a scientific basis to explain the use of C.mongolica in traditional and complementary medicine.

\section{ACKNOWLEDGEMENTS}

The author thank to the financial support by InterInstitutional Collaboration Research Program under Korea Research Council for Industrial Science and Technology.

\section{REFERENCES}

1. Grubov V.I. Key to the vascular plants of Mongolia, Ulaanbaatar, (2008) 170.

2. Ligaa U., Davaasuren B., Ninjil N. Medicinal plants of Mongolia used in western and eastern medicine, JKC printing, Ulaanbaatar, (2006) 483-484.

3. Ligaa $U$. Methods of the usage of Mongolian medicinal plants and complex formulations in the Mongolian traditional medicine, Ulaanbaatar, (1996) 271-272.

4. Holzer V.M.D, Lower-Nedza A.D., Nandintsetseg M., Batkhuu J., Brantner A.H. (2013) Antioxidant constituents of Cotoneaster melanocarpus Lodd. Antioxidants, 2, 265-272. doi:10.3390/ antiox2040265

5. Esmaeili S., Ghiaee A., Naghibi F., Mosaddegh. (2015) Antiplasmodial activity and cytotoxicity of plants used in traditional medicine of Iran for the treatment of fever. Iran. J. Pharm. Res., 14, 103107.

6. Azadbakht M., Pishva N., Mohammadi-Samani S., Alinejad F. (2005) The effect of purgative manna on the infant jaundice. Iran. J. Pharm. Sci., 1, 95-100.

7. Jerzak E., Cotoneaster species cultivated in Poland (in Polish); Officina Botanica: Krakov, Poland, (2007).

8. Slabaugh P.E., Shaw N.L. Cotoneaster Medik. The Woody Plant Seed Manual; Bonner F.T., Karrfalt R.P. Eds.; U.S. Department of Agriculture, Forest Service: Washington DC, USA, (2008) 442-446.

9. Chang Ch-S., Jeon J-I. (2003) Leaf flavonoids in Cotoneaster wilsonii (Rosaceae) from the island Ulleong-do, Korea. Biochem. Syst. Ecol., 31, 171179. doi:10.1016/S0305-1978(02)00064-9

10. Stahl E., Kaltenbach U. in Zukher und Derivative in Duennschicht-Chromatographie, ein Laboratorium
Handbuch, Ed. Stahl E., Springer-Verlag, Berlin, (1962) 473.

11. Mensor L.L., Menezes F.S., Leitao G.G., Reis A.S., Santos T.C., Coude C.S., Leitao S.G. (2001) Screening of Brazilian plant extracts for antioxidant activity by use of DPPH free radical method. Phytother. Res., 15, 127-130. doi:10.1002/ptr.687

12. Ellman G.L., Courtney K.D., Feater-Stone Andres V.Jr.R.M. (1961) A new and rapid colorimetric determination of acetylcholinesterase activity. Biochem. Pharmacol., 7, 88-95. doi:10.1016/00062952(61)90145-9

13. Kicel A., Michel P., Owczarek A., Marchelak A., Zyzelewicz D., Budryn G., Oracz J., Olszewska M.A. (2016) Phenolic profile and antioxidant potential of leaves from selected Cotoneaster Medik. species. Molecules, 21(6), 688. doi:10.3390/ molecules21060688

14. Sokkar N., El-Gindi O., Sayed S., Mohamed Sh., Ali Z., Alfishawy I. (2013) Antioxidant, anticancer and hepatoprotective activities of Cotoneaster horizontalis Decne extract as well as a-tocopherol and amygdalin production from in vitro culture. Acta Physiol. Plant, 35, 2421-2428. doi:10.1007/ s11738-013-1276-z

15. Zengin G., Uysal A., Gunes E., Aktumsek A. (2014) Survey of phytochemical and biological effects of three extracts from a wild plant (Cotoneaster nummularia Fisch. et Mey): A potential source for functions; food ingredients and drug formulations, 9(11), e113527. doi:10.1371/journal.pone.0113527

16. Uysal A., Zengin G., Mollica A., Gunes E., Locatelli M., Yilmaz T., Aktumsek A. (2016) Chemical and biological insights on Cotoneaster integerrimus: $A$ new (-) - epicatechin source for food and medicinal applications. Phytomed., 23, 979-988. doi:10.1016/ j.phymed.2016.06.011

17. Odontuya G. (2016) Anti-oxidative, acetylcholin -esterase and pancreatic lipase inhibitory activities of compounds from Dasiphora fruticosa, Myricaria alopecuroides and Sedum hybridum. Mon. J Chem., 17(43), 42-49. doi:10.5564/mic.v17i43.746

18. Markham K.R, Ternai B., Stanley R., Geiger H., Mabry T.J. (1978) Carbon-13 NMR studies of flavonoids - III, Tetrahedron, 34, 1389-1397. doi:10.1016/0040-4020(78)88336-7

19. Harborne J.B., The flavonoids, Advances in research since 1986. Chapman and Hall: London; (1994) 448-496.

20. Yim S-H., Lee Y-J., Park K-D., Lee I-S., Shin B-A., Jung D-W., Williams D.R., Kim H-J. (2015) Phenolic constituents from the flowers of Hamemelis japonica Sieb. et Zucc. Nat. Prod. Sci., 21(3), 162169.

21. Fuchino H., Nakamura H., Wada H., Hakamatsuka T., Tanaka N. (1997) 5-O-Glucosylated kaempferols from the fern Dryopteris dickinsii. Nat. Med., 51(6), 537-538. 
22. Vitor R.F., Mota-Filipe H., Teixeira G., Borges C., Rodrigues A.I., Teixeira A., Paul A. (2004) Flavonoids of an extract of Pterospartum tridentatum showing endotheilial protection against oxidative injury. J. Ethnopharmacol., 93, 363-370. doi:10.1016/j.jep.2004.04.003

23. Seebacher W., Simic N., Weis R., Saf R., Kunert O. (2003) Complete assignments of ${ }^{1} \mathrm{H}$ and ${ }^{13} \mathrm{C}$ NMR resonances of oleanolic acid, 18a-oleanolic acid, ursolic acid and their 11-oxo derivatives. Magn. Reson. Chem., 41, 636-638. doi:10.1002/mrc.1214

24. Woo K-W., Han J-Y., Choi S-U., Kim K-H., Lee K-R. (2014) Triterpenes from Perilla frutescens var. acuta and their cytotoxic activity. Nat. Prod. Sci., 20(2), 71-75.

25. Seigler D.S., Pauli G.F., Nahrstedt A., Leen R. (2002) Cyanogenic allosides and glucosides from Passiflora edulis and Carica papaya. Phytochem., 60, 873-882 doi:10.1016/s0031-9422(02)00170-x

26. D'Abrosca B., DellaGreca M., Fiorentino A., Monaco P., Previtera L., Simonet A.M., Zarelli A. (2001) Potential allelochemicals from Sambucus nigra. Phytochem., 58, 1073-1081. doi:10.1016/ S0031-9422(01)00401-0

27. Yuda M., Ohtani K., Mizutani K., Kasai R., Tanaka O., Jia M-R., Ling Yi-R., Pu X-F., Saruwatari Y-I. (1990) Neolignan glycosides from roots of Codonopsis tangshen. Phytochem., 29(6), 19891993. doi:10.1016/0031-9422(90)85053-I

28. Hamerski L., Bomm M.D., Silva D.H.S., Young M.C.M., Furlan M., Eberlin M.N., CastroGamboa I., Cavalheiro A.J., Bonzani V. da S. (2005) Phenylpropanoid glucosides from leaves of Coussarea hydrangeifolia (Rubiaceae). Phytochem., 66, 1927-1932. doi:10.1016/j. phytochem.2005.06.019

29. Klick S., Herrmann K. (1988) Glucosides and glucose esters of hydrobenzoic acids in plants. Phytochem., 27(7), 2177-2180. doi:10.1016/00319422(88)80121-3

30. Nahrstedt A. (1973) Cyanogenesis in Cotoneaster-Arten. Phytochem., 12, 1539-1542 doi:10.1016/0031-9422(73)80364-4
31. Palme E., Bilia A.R., Morelli I. (1996) Flavonols and isoflavones from Cotoneaster simonsii. Phytochem., 42, 3, 903-905. doi:10.1016/00319422(95)00023-2

32. Praeventio N.G.O. (2014) Dependence of DPPH radical scavenging activity of dietary flavonoids quercetin on reaction environment, Med. Chem., 14, 494-504. doi:10.2174/1389557514666140622 $\underline{204037}$

33. Jung M., Park M. (2007) Acetylcholinesterase inhibition by flavonoids from Agrimonia pilosa, Molecules, 12, 2130-2139. doi:10.3390/12092130

34. Orhan I., Kartal M., Tosun F., Sener B. (2007) Screening of various phenolic acids and flavonoid derivatives for their anticholinesterase potential, Z. Naturforsch., C 62, 829-832. doi:10.1515/znc2007-11-1210

35. Vila-Nova N.S., Morais S.M., Falcao M.J., Bevilaqua C.M., Rondon F., Wilson M.E., Vieira I.G., Andrade H.F. (2012) Leishmanicidal and cholinesterase inhibiting activities of phenolic compounds of Dimorphandra gardeniana and Platymiscium floribundum, native plants from Caatinga biome, Pesqui. Vet. Bras., 32, 1164-1168.

36. Zhao Y., Dou J., Wu T., Aisa H.A. (2013) Investigating the antioxidant and acetylcholinesterase inhibition activities of Gossypium herbaceam. Molecules, 18, 951-962. doi:10.3390/molecules18010951

37. Park J-Y., Han X., Piao M-J., Oh M-Ch., Fernando P.M.D.J., Kang K-A., Ryu Y-S., Jung U., Kim I-G., Hyun J-W. (2016) Hyperoside induces endogenous antioxidant system to alleviate oxidative stress. J. Cancer Prev., 21(1), 41-47. doi:10.15430/ JCP.2016.21.1.41

38. Raza A., Xu X., Sub H., Tang J., Ouyang Z. (2017) Pharmacological activities and pharmacokinetic study of hyperoside: A short review. Trop. J. Pharm. Res., 16(2), 483-489. doi:10.4314/tjpr.v16i2.30

39. Khan H., Marya, Amin S., Kamal M.A., Patel S. (2018) Flavonoids as acetylcholinesterase inhibitors: Current therapeutic standing and future prospects, Biomed. Pharmacother., 101, 860-870. doi:10.1016/j.biopha.2018.03.007 